\title{
Effects of Breast Cancer Treatment on Posture: A Current Review
}

\author{
Jackeline Rangel $^{4,}$, Carla S. Perez ${ }^{1,2}$, Raul Oliveira ${ }^{3}$ and Elaine C.O. Guirro ${ }^{1,2}$ \\ ${ }^{1}$ Postgraduate Program in Rehabilitation and Functional Performance, São Paulo University, Ribeirão Preto, São Paulo, Brazil \\ ${ }^{2}$ Department of Health Science, Ribeirão Preto Medical School, University of São Paulo, Ribeirão Preto-SP, Brazil \\ ${ }^{3}$ CIPER, Faculdade de Motricidade Humana, Universidade de Lisboa, Lisboa, 1649-004, Portugal \\ ${ }^{4}$ Faculdade de Motricidade Humana, Universidade de Lisboa, Lisboa, 1649-004, Portugal
}

\section{Abstract}

The treatment of breast cancer can trigger several functional limitations and postural changes. The asymmetry of the shoulder girdle and trunk and greater forward leaning of the trunk are the major expected changes in posture. Stress and mechanical asymmetries caused by these postural changes may have clinical and functional repercussions, generating joint problems and inadequate muscular tension. Physical therapy is considered an effective intervention for pain control, postural realignment and recovery of functional autonomy. The aim of this review is to characterise the main postural dysfunctions observed after the treatment of breast cancer and to succinctly identify the main strategies of physiotherapeutic intervention to prevent and/or treat these alterations.

\section{Publication History:}

Received: June 08, 2019

Accepted: June 27, 2019

Published: June 29, 2019

Keywords:

Breast Cancer, Mastectomy, Posture, Rehabilitation; Physiotherapy

\section{Introduction}

Breast cancer, the most common cancer in women, is a major public health problem. The development of new diagnostic and therapeutic resources has increased the survival rates of this population [1]. The treatment of breast cancer can trigger several morbidities such as lymphedema, neck pain, pain and limitation of movements of the joint complex of the shoulder, sensory disturbances and changes in kinematics and biomechanics of the upper limb same side to surgery and the trunk $[2,3]$.

Breast cancer treatment currently involves surgical removal of the breast tumour, total or partial excision of the axillary lymph nodes and, according to the tumour typology, possible treatment involving chemotherapy, radiotherapy and hormone therapy $[4,5]$. Surgeries involving breast cancer treatment may result in conservative surgeries or mastectomy or total breast withdrawal, with or without breast reconstruction [6]. With advancements in health care, from better prevention to the best treatment, conservative breast surgeries and breast reconstructions are becoming more and more common. Studies are unanimous in saying that mastectomies present greater morbidity when compared to breast reconstructions and conservative surgeries [7-11].

Mastectomy may lead to postural changes, particularly in the trunk and upper limb on the same side as the surgery, due to the significant asymmetry of soft tissues and a change in the mass distribution in the chest wall, together with the complications of treatment, such as pain and fibrosis [12-15]. These changes may be present soon after surgery and/or remain for years after treatment [16]. The mechanical stress caused by changes in posture can have clinical and functional repercussions with effects on the connective, muscular and joint tissues, altering the distribution of load and pressure; this may contribute to degenerative joint alterations and inadequate muscular tension [18]. Although post-mastectomy pain is considered essentially neuropathic [19], there is more recent evidence that stress in myofascial tissues is a relevant causal factor, since it may provoke myofascial syndrome $[20,21]$.

While surgery and radiotherapy continue as pillars of breast cancer treatment, physiotherapy should be more focused on the rehabilitation and recovery of upper body strength and flexibility [22]. Recent findings regarding the postural alterations of women after breast cancer treatment, especially after mastectomy, recommend a greater investigation of alterations to the posture of patients during cancer treatment and in survivors of the disease [23].

The assessment of postural changes in the trunk and upper limb helps to understand potential functional changes and then to plan an intervention in order to prevent and/or minimise complications that affect breast cancer survivors throughout their lives. It is also crucial to implement programs with the objective of minimising the risks of occurrence and to improve the quality of life of these women. The increased life expectancy of women diagnosed with breast cancer suggests that many of these women may be living with the sequelae of treatment. The main objective of this review is to characterise postural dysfunctions after breast cancer treatment and to succinctly identify the main intervention strategies, such as physiotherapy, with regard to prevention and treatment.

\section{Posture and Postural Control: Concepts and Methods of Analysis}

Posture can be defined as the biomechanical alignment of the body and its orientation to the environment [24]. Currently, there are several quantitative methods available for postural analysis, including biophotogrammetry, which is a reliable method of obtaining posture information through the interpretation of photographic images, allowing for the quantification of human body measurements and analysing the relationship between their segments. The main advantages of this approach are that they allow for an evaluation of the entire body using the same image $[25,26]$. However, for a good evaluation, the photos must be high-quality and distortion-free, the equipment must be accurately adjusted and remain in the same

"Corresponding Author: Dr. Jackeline Rangel, PT, MSc in Physical Therapy and PhD student in Faculdade de Motricidade Humana-Universidade de Lisboa, Portugal; E-mail: jackelinerangel@gmail.com

Citation: Rangel J, Perez CS, Oliveira R, Guirro ECO (2019) Effects of Breast Cancer Treatment on Posture: A Current Review. Int J Phys Ther Rehab 5: 152. doi: https:// doi.org/10.15344/2455-7498/2019/152

Copyright: (C) 2019 Rangel et al. This is an open-access article distributed under the terms of the Creative Commons Attribution License, which permits unrestricted use, distribution, and reproduction in any medium, provided the original author and source are credited. 
position throughout the analysis, and the environment should be properly illuminated and provide privacy to the assessed patient [27].

Biophotogrammetry and radiography are both methods for assessing spinal alignment [28]. However, radiography is considered the gold standard for the quantification of spine angles from calculations, with reference to the vertebrae visible on the radiographic examination [29]. The commonly used method is the Cobb angle, used to measure frontal deformity by the intersection of a straight line drawn from the endplate of a vertebra and a straight line drawn from the endplate of another vertebra of reference [30,31]. In mastectomised patients, where there may be adjuvant treatments involving radiation, biophotogrammetry is a simple and easy-to-apply alternative, with a low cost of clinical application, ease of photo interpretation, high precision and facile reproduction of results [19] with an objective and quantitative analysis. It is commonly used among studies on postural evaluation in this population. Postural analysis should integrate a clinical evaluation from the beginning of physiotherapy and if possible before surgery, to know the dominant posture before the surgical intervention. With the alignment of the body segments, the hypothesis of a better distribution of load and better mechanical organisation for soft tissues and joints is created. The objective of the intervention is to lead the patient to the level closest to the reference standard considered to be ideal $[24,27]$. The understanding of posture involves the concept of postural control, posture and stability, so the alignment of body segments and postural changes affect the location of the centre of gravity, which may have repercussions on changes in body stability [24].

Postural control is the position of the body in space, with two objectives. The first is postural stability, which is the ability to keep the body in balance. The second is postural orientation, defined as the ability to maintain an appropriate relationship between body segments and between the body and the environment when performing a task with stability and orientation [32]. The centre of pressure (COP) is the vertical projection of the forces produced during movements or when in a static position. However, the velocities and accelerations of the individual segments and joints are so small that the vast majority of optical systems are not precise enough to produce significant kinematic data, so a force platform is used, where the main variable is COP [33]. COP oscillations reflect only operative level of postural control related to the orientation of postural control in a specific posture and the orientation of body segments [34].

Changes in postural alignment may trigger mechanical changes [35]. Postural control is responsible for different posture functions. In a situation of postural misalignment, motor behaviour is soon altered [36].

\section{Postural Changes After Breast Cancer Treatment and the Influence of Breast Reconstruction}

The indication among the different types of surgical interventions in breast cancer depends on the clinical condition and histology of the tumour, and may vary between mastectomy and conservative treatment with resection of a breast segment and removal of axillary lymph nodes or sentinel lymph nodes [6]. Postural changes may occur after cancer treatment, such as protraction of the shoulders, a limited arm movement range, scapular misalignment, pain and altered sensitivity in the arm and axilla on the same side as the surgery $[37,38]$.
An evaluation performed through photogrammetry assessed the anteroposterior curves of the spine in 51 women an average of 6.5 years after surgical treatment for breast cancer, where a Pateytype radical mastectomy was the most frequent approach (84.3\%), chemotherapy (54\%), hormone therapy (66\%), and unilateral surgery (92\%); the majority of patients were submitted to adjuvant treatment with radiotherapy (88\%). Postural alterations were observed in $82.3 \%$ of women who underwent breast cancer treatment, compared to only $35.1 \%$ in women who did not undergo this type of treatment [37].

Another study performing a postural evaluation through photogrammetry observed that the main alterations found in 85 mastectomised women were asymmetry of the shoulder girdle and the trunk and greater forward leaning of the trunk. It was also observed that the operated side scapula was located higher than the opposite side [38], suggesting a change in the activation and coordination of the stabilising muscles of the scapula, such as shortening and/or decreased shoulder muscle strength [39]. The scapular girdle region was the site where the greatest changes were found both in relation to posture and problems with function, also with higher levels of pain that may remain until years after the surgery $[40,41]$. In relation to the anteroposterior curvature of the spine, there is a tendency to increased thoracic kyphosis among women after mastectomy compared to women who did not receive this type of treatment, also seen through photogrammetry [42]. When investigating the correlation between trunk muscle function and body posture in 50 mastectomised women, it was possible to observe alterations in the anteroposterior curve of the vertebral column, which can lead to functional disturbances to the trunk muscles, as well as greater involvement of the trunk musculature in women with a lordotic posture [43].

The time after surgery is a factor that should be considered when analysing the posture of women who have undergone breast cancer treatment, since body posture changes over time after surgery. In the immediate postoperative period, this is related to forward leaning of the trunk, followed by backward leaning of the trunk years later; it should be assumed that leaning from the trunk forward a short time after the operation is an analgesic and protective position that passes with time [38]. Post-surgical pain, including mastectomy surgeries and immediate or late reconstructive surgeries, may lead to scar tissue formation and the adoption of a protective stance, leading to shortening of the soft tissues of the anterior chest wall, including the pectoral muscles major and pectoralis minor, and may result in depression of the scapula in the frontal plane [12]. Abnormal positioning of the scapula leads the muscles of the shoulder girdle to alter their tension and length relationships, resulting in a functional imbalance [44].

Adopting an antalgic posture such as thoracic spine flexion and scapular protraction may aggravate the muscle shortening and force reduction described above. The application of radiotherapy and the consequent fibrosis can further aggravate this condition by producing more tension in the soft tissues $[45,46]$. Myofascial trigger points are present in dysfunctional muscles and are associated with breast cancer survivors [20]. In addition to pain, myofascial dysfunctions may also contribute to an altered posture [14,47]. A longitudinal study, performed six months after mastectomy, showed a painful syndrome in $52 \%$ of the participants and $27.2 \%$ of the patients reported pain in the shoulders and in the scapulo-thoracic region [48]. The distribution of mass in the trunk can influence the posture, thus the size of the breasts can condition the postural alignment [49]. The size of the breasts ends up influencing the posture, as it conditions the location 
of the centre of gravity and, in turn, the physiological curvature of the spine [50]. The centre of pressure oscillation is greater in women with large breasts, compared to the control group. In addition to that, the oscillation of the pressure centre decreases in women after reductive mammoplasty [51,52]. Breast size is a factor that influences body posture, with a greater tendency to change posture after mastectomy.

Breast reconstructions are becoming more and more common, and reconstructions with implants are the most commonly used procedures [53]. Myocutaneous flaps, despite having relatively high rates of complications, are also widely used [54,55]. These include the dorsal large muscle flap, the abdominal flap (vertical or transverse) and the external oblique muscle [56]. Women after radical mastectomy with immediate breast reconstruction, evaluated six months after surgery, presented significantly fewer postural changes compared to women who did not have their breast reconstructed after mastectomy. Moreover, the posture of women after mastectomy with immediate reconstruction of the breast was comparable with the posture of women without the disease [7]. The posture of mastectomised women when compared to women submitted to myocutaneous reconstruction of the rectus abdominus after one to five years showed no difference in terms of the alignment of the head, shoulders, scapula and pelvis. However, differences were observed in the vertical alignment of the trunk, measured by the angle between the vertical line and another line connecting the acromion to the greater trochanter of the femur, which indicates a rotation of the trunk since the position of the shoulder is more posterior than that of the femur. As this change was unilateral, it reinforces the hypothesis of trunk rotation [57] In the long run, women who underwent immediate reconstruction after mastectomy did not show significant changes in body posture during 24 months of observation. The group of women submitted to reconstruction and a group of women without surgical intervention did not present significant differences [13]. A case-control study performed with conservative breast surgeries found a lower incidence of postural changes [58].

By means of radiographic images, in a preoperative temporal analysis and two years after treatment, unilateral mastectomy led to a change in chest cavity symmetry with implications on the weightbearing mechanism of the spine. Patients who underwent unilateral mastectomy with immediate reconstruction showed minor changes in postoperative vertebral alignment and the Cobb angle, measured through a parallel line between the T4 and T11 vertebrae and the coronal alignment of the vertebrae body. Additionally, alterations in postoperative vertebral alignment were significantly lower in patients who received immediate breast reconstruction [59].

Absence of the breast can lead to changes throughout the body, and can even be seen in the feet. In an evaluation by means of a podoscope, where the foot shape and weight support in the lower limbs were evaluated, there were differences in foot shape on the

same side as the operated breast, which can be explained by asymmetry in the transfer of weight placed in each half the side, a negative long-term consequence of mastectomy [16]. On the other hand, conservative breast surgery did not present significant alterations in the posture of the foot on the same side of the breast surgery, and the same was found on the opposite side to the surgery. This situation was maintained in the short and long term [60].

Immediate breast reconstruction has been shown to have few adverse effects on body posture, because there is no period without the breast. Therefore, immediate breast reconstruction leads to a better postoperative result, not only in terms of aesthetic results and patient self-esteem, but through the prevention of complex alterations in body posture, positively affecting the alignment of the spine and leading to a better posture and physical function [59]. Although women who underwent immediate breast reconstruction had the effects of surgery such as the presence of fibrosis, shortening of the major and minor pectoral muscles and pain, as well as alterations to the angle of the homolateral shoulder blade after surgery, the morbidities found in mastectomised women were greater than those in women who underwent breast reconstruction [13,57].

\section{Strategies for the Prevention and Treatment of Postural Changes after Breast Cancer Treatment}

When recognising the expected postural changes and their causes after breast cancer treatment, it is important to establish strategies for the prevention and treatment of breast cancer.

According to a cross-sectional study of 94 breast cancer survivors aged 23-72, they said that physical therapy was important at all stages of treatment and helped overcome the side effects of treatment. In addition, physical activity decreased the occurrence of musculoskeletal complications associated with treatment, such as pain and movement limitations [61]. These findings can be explained by another study showing that the practice of regular physical activity in mastectomised women can have a positive effect on postural reeducation, such as maintaining the levelling of the angles of body inclination, improving trunk symmetry, as well as the position of the scapulae and scapular girdle [38]. Phytotherapeutic interventions also have positive effects on other variables. Identifying triggering factors such as posture is critical so that pain relief does not have a transient effect [12]. Breast cancer survivors have higher pain intensity in the upper trapezius muscle compared to women with neck pain, which indicates the need for specific assessments and interventions for myofascial dysfunction in these women [62]. Stretching and strengthening exercises associated with ischemic compression of trigger points favour postural improvement, pain relief and functional autonomy with a positive impact on pain and posture $[20,21]$.

Considering the tendency of trunk rotation in mastectomised women without breast reconstruction [57], physiotherapy should include preventive exercises aiming to improve trunk stabilisation and the symmetry of the upper limbs. Postural adjustments do not result from rigid internal structures, but can be modified by time and learning, which makes these changes amenable to treatment through a rehabilitation program [36]. The physiotherapy program should take into account the specific procedure used for breast reconstruction. Unlike the simple placement of a prosthesis, the procedure may have involved myocutaneous flaps of muscles such as the large dorsal and transverse abdominus rectus, which plays different roles in maintaining body alignment and trunk and limb functionality. The choice of exercises may be more specific based on this information, and compensatory changes in posture can be avoided [57]. There is evidence that both Nordic walking and resistance exercises in the water are capable of triggering positive postural changes in women surviving breast cancer. However, women who practice only non-specific exercises do not obtain these gains in postural improvement. These results indicate the need to broaden our knowledge on the subject and to perform new research using modern methods to rehabilitate the posture of mastectomised women. The diversity observed in the form of anteroposterior spinal curvatures after physical training regimens of 
different types and natures demonstrates the need for adequate exercise selection to achieve the desired therapeutic outcome [64] Adherence to exercise is still a challenge for women undergoing breast cancer treatment, and changes to traditional modes of rehabilitation are necessary [65]. Compared with conventional training in therapeutic exercises, the Pilates method offers the potential to reduce biomechanical dysfunctions that can occur as a result of cancer therapy through improvements in body awareness and kinaesthetics [66]; it is also used to improve postural alignment [67]. The Pilates method can be safely prescribed for women after treatment for breast cancer. Pilates practice can alleviate the impact of cancer-related symptoms and improve the quality of life of patients. Compared with other exercise interventions, Pilates appears to be especially effective in improving upper limb pain and function [68].

\section{Key Clinical Points}

1. Treatment of breast cancer can lead to side effects that may contribute to postural changes, mainly involving the cervicodorsal spine, shoulders and scapular girdle that can lead to chronic functional limitations and pain.

2. In women who are survivors of breast cancer, there is a need for a postural analysis using reliable, accurate and replicable methods of analysis, since it will directly influence the choice of therapy.

3. Immediate breast reconstruction reduces the morbidity related to immediate and late postural changes compared to total mastectomy without reconstruction, thereby reducing treatment complications.

4. Mastectomised women have greater morbidity than women who have undergone breast reconstruction and lumpectomy, although there is a shortage of studies in this population. The importance of these studies becomes increasingly necessary as more of these surgeries are performed.

5. A rehabilitation program for women undergoing breast cancer treatment should include a physiotherapy/movement-specific approach to the rehabilitation of posture and pain management. The practice of regular physical activity should be encouraged, supplemented by other methods that stimulate body awareness and postural control like the Pilates method.

\section{Competing Interests}

The authors declare that they have no competing interests.

\section{Acknowledgements}

This study was financed in part by the Coordenação de Aperfeiçoamento de Pessoal de Nível Superior - Brasil (CAPES) Finance Code 88881.190398/2018-01.

\section{References}

1. Tao Z, Shi A, Lu C, Song T, Zhang Z, et al. (2015) Breast Cancer: Epidemiology and Etiology. Cell Biochem Biophys 72:333-338.

2. Bossombra K, Ashicaga T, O'Brien PJ, Nelson L, Skelly J, et al. (2002) Swelling, numbness, pain, and their relationship to arm function among breast cancer survivors: a disablement process model perspective. Breast J 8: 338-348.

3. Meric F, Buchholz TA Mirza NQ, Vlastos G, Ames FC, et al. (2002) Longterm complications associated with breast-conservation surgery and radiotherapy. Ann Surg Oncol 9: 543-549.
4. Oliveira CF, Custódio S (2007) Histoire du traitement conservateur du cancer du sein. Place de la chirurgie. Le Sein - du Normal au Pathologique: État de l'Art. Eska 3: 821-36.

5. Dimitrov G, Baytchev G, Inkov I, Dimitrov D (2017) The advancement and history of breast cancer surgical therapy at a glance. International Journal of Surgery and Medicine 2:1-10.

6. Petit J, Rietjens M, Garusi C (2001) Breast reconstructive techniques in cancer patients: which ones, when to apply, which immediate and long term risks?. Crit Rev Oncol Hematol 38: 231-239.

7. Malgorzata B, Ciesla S (2009) Assessment of postural disorders in women after radical mastectomy followed by immediate breast reconstruction. Fizjoterapia 17: 30-37.

8. Howes BH, Watson DI, Xu C, Fosh B, Canepa M, et al. (2016) Quality of life following total mastectomy with and without reconstruction versus breastconserving surgery for breast cancer: A case-controlled cohort study. J Plast Reconstr Aesthet Surg 69: 1184-1191.

9. Rowland JH, Holland JC, Chaglassian T, Kinne D (1993) Psychological response to breast reconstruction. Expectations for and impact on postmastectomy functioning. Psychosomatics 34: 241-250.

10. Jeevan R, Mennie JC, Mohanna PN, O'Donoghue JM, Rainsbury RM, et al. (2016) National trends and regional variation in immediate breast reconstruction rates. Br J Surg 103: 1147-1156.

11. Fisher B, Anderson S, Bryant J, Margolese RG, Deutsch M, et al. (2002) Twenty-year follow-up of a randomized trial comparing total mastectomy, lumpectomy, and lumpectomy plus irradiation for the treatment of invasive breast cancer. N Engl J Med 347: 1233-1241.

12. Cheville AL, Tcgou J (2007) Barriers to rehabilitation following surgery for primary breast cancer. J Surg Oncol 95: 409-418.

13. Ciesla S, Polom K (2010) The effect of immediate breast reconstruction with Becker-25 prosthesis on the preservation of proper body posture in patients after mastectomy. Eur J Surg Oncol 36: 625-631.

14. Stubblefield MD, Keole N (2013) Upper body pain and functional disorders in patients with breast cancer. PM \& R 6: 170-183.

15. Shamley D, Lascurain-Aguirrebeña I, Srinaganathan RO, Ragavan (2012) Shoulder morbidity after treatment for breast cancer is bilateral. Acta Oncologica 51: 1045-1053.

16. Głowacka-Mrotek I, Sowa M, Nowikiewicz T, Siedlecki Z, Hagner W, et al. (2017) Foot posture in female patients 5 years after breast-conserving surgery: a case-control study. Breast Cancer 25: 325-333.

17. Harrison AL, Barry-Greb T, Wojtowicz G (1996) Clinical measurement of head and shoulder posture variables. J Orthop Sports Phys Ther 23: 353361.

18. Riegger-Krugh C, Keysor JJ (1996) Skeletal malalignments of the lower quarter: correlated and compensatory motions and postures. J Orthop Sports Phys Ther 23: 164-170.

19. Wallace SW, Wallace AM, Lee J, Dobke MK (1996) Pain after breast surgery: A survey of 282 women. Pain 66: 195-205.

20. Fernández-Lao $C$, Cantarero-Villanueva I, Fernández-de-Las-Peñas $C$ Del-Moral-Ávila R, Menjón-Beltrán S, et al. (2012) Development of active myofascial trigger points in neck and shoulder musculature is similar after lumpectomy or mastectomy surgery for breast cancer. J Bodyw Mov Ther 16: 183-190.

21. Rangon FB, Koga Ferreira VT, Rezende MS, Apolinário A, Ferro AP, et al. (2018) Ischemic compression and kinesiotherapy on chronic myofascial pain in breast cancer survivors. J Bodyw Mov Ther 22: 69-75.

22. Collins LG, Nash R, Round T, Newman B (2004) Perceptions of upper-body problems during recovery from breast cancer treatment. Support Care Cancer 12: 106-113.

23. van Abellan Kan G, Rolland Y, Andrieu S, Beauchet O, et al (2009) Gait speed at usual pace as a predictor of adverse outcomes in community-dwelling older people an International Academy on Nutrition and Aging (IANA) Task Force. J Nutr Health Aging 13: 881-889.

24. Danis CG, Krebs DE, Gill-Body KM, Sahrmann S (1998) Relationship between standing posture and stability. Phys Ther 78: 501-519.

25. Singla D, Veqar Z (2014) Methods of postural assessment used for sports persons. J Clin Diagn Res 8: 1-4.

26. Barrett E, Mccreesh K, Lewis J (2014) Reliability and validity of nonradiographic methods of thoracic kyphosis measurement: A systematic review. Man Ther 19:10-17. 
27. Watson AWS (1998) Procedure for the production of high quality photography suitable for the recording and evaluation of the posture. Rev Fisioter 5: 20-26

28. Porto $A B$, Okazaki VHA (2017) Procedures of assessment on the quantification of thoracic kyphosis and lumbar lordosis by radiography and photogrammetry: A literature review. J Bodyw Mov Ther 21: 986-994.

29. De Carvalho DE, Soave D, Ross K, Callaghan JP (2010) Lumbar spine and pelvic posture between standing and sitting: a radiologic investigation including reliability and repeatability of the lumbar lordosis measure. Manip Physiol Ther 33: 48-55.

30. Harrison D, Cailliet R, Harrison DD, Janik TJ (2002) How do anterior/ posterior translations of the thoracic cage affect the sagittal lumbar spine pelvic tilt, and thoracic kyphosis? Eur Spine J 11: 287-293.

31. Kado DM, Christianson L, Palermo L, Smith-Bindman R, Cummings SR, et al (2006) Comparing a supine radiologic versus standing clinical measurement of kyphosis in older women: the fracture intervention trial. Spine 3: 463-467.

32. Shumway-Cook A, Woollacott (2000) Motor Control-Theory and Practical applications. Lippincott Williams \& Wilkins ed.

33. Winter DA, Patla AE, Ishac M, Gage WH (2003) Motor mechanisms of balance during quiet standing. J Electromyogr Kinesiol 13: 49-56.

34. Ivanenko Y, Gurfinkel VS (2018) Human Postural Control. Front Neurosci 20: $12-171$.

35. Freeres M, Mairlot MB (1997) Maítres et clés de la posture. Paris: FrisonRoche.

36. Mochizuki L, Amadio AC (2003) The Function of postural during standing Physiot São Paulo 10: 7-15.

37. Malicka I, Barczyk K, Hanuszkiewicz J, Skolimowska B, Wozniewski M, et al. (2010) Body posture of women after breast cancer treatment. Ortop Traumatol Rehabil 12:353-361.

38. Rostkowska E, Bak M, Samborski W (2006) Body posture in women after mastectomy and its changes as a result of rehabilitation. Adv Med Sci 51 287-297.

39. Burkhart SS, Morgan CD, Kibler WB (2003) The disabled throwing shoulder: spectrum of pathology Part III: The SICK scapula, scapular dyskinesis, the kinetic chain, and rehabilitation. Arthroscopy 19: 641-661.

40. Shamley D, Srinaganathan R, Oskrochi R, Lascurain-Aguirrebeña I, Sugden $E_{\text {, et }}$ al. (2009) Three-dimensional scapulothoracic motion following treatment for breast cancer. Breast Cancer Res Treat 118: 315-322.

41. Crosbie J, Kilbreath SL, Dylke E, Refshauge KM, Nicholson LL, et al. (2010) Effects of mastectomy on shoulder and spinal kinematics during bilatera upper-limb movement. Phys Ther 90: 679-692.

42. Malicka I, Hanuszkiewicz J, Stefańska M, Barczyk K, Woźniewski M, et al. (2010) Relation between trunk muscle activity and posture type in women following treatment for breast cancer. J Back Musculoskelet Rehabil 23: 11 19.

43. Hanuszkiewicz J, Malicka I, Stefańska M, Barczyk K, Woźniewski M (2011) Body posture and trunk muscle activity in women following treatment of breast cancer. Ortop Traumatol Rehabil 13: 45-57.

44. Borg-Stein J, Simons DG (2002) Focused review: Myofascial pain. Arch Phys Med Rehabil 83: 40-47.

45. Ebaugh D, Spinelli B, Schmitz KH (2011) Shoulder impairments and their association with symptomatic rotator cuff disease in breast cancer survivors. Med Hypotheses 77: 481-487.

46. Kim SM, Park JM (2004) Normal and abnormal US findings at the mastectomy site. Radiographics 24: 357-365.

47. Hayes SC, Johansson K, Stout NL, Prosnitz R, Armer JM, et al. (2012) Upperbody morbidity after breast cancer: incidence and evidence for evaluation prevention, and management within a prospective surveillance model of care. Cancer 118: 2237-2249.

48. Alves Nogueira Fabro E, Bergmann A, do Amaral E Silva B, Padula Ribeiro AC, de Souza Abrahão K, et al. (2012) Post-mastectomy pain syndrome: incidence and risks. Breast 2: 321-325.

49. Lapid O, de Groof EJ, Corion LU, Smeulders MJ, van der Horst CM (2013) The effect of breast hypertrophy on patient posture. Arch Plast Surg 40: 559-563.

50. Fernandes PM, Neto MS, Veiga DF, Abla LEF, Mundim CDA, et al. (2007) Back Pain: an assessement in breast hypertrophy patients. Acta Orto Bras 15:227-230.
51. Barbosa AF, Lavoura PH, Boffino CC, Siqueira CM, Costa MP, et al. (2013) The impact of surgical breast reduction on the postural control of women with breast hypertrophy. Aesthetic Plast Surg 37: 321-326.

52. Barbosa AF, Raggi GC, Cardoso Sá CS, Costa MP, Lima Jr JE, et al. (2012) Postural control in women with breast hypertrophy. Clinics 67: 757-760.

53. Jeevan R, Mennie JC, Mohanna PN, O'Donoghue JM, Rainsbury RM, et al. (2016) National trends and regional variation in immediate breast reconstruction rates. Br J Surg 103: 1147-1156.

54. Park TH, Rah DK, Chong Y, Kim JK (2015) The effects of botulinum toxin a on survival of rat TRAM flaps with vertical medline scar. Ann Plast Surg 74: 100-106.

55. Tasoulis MK, Iqbal FM, Cawthorn S, MacNeill F, Vidya R (2017) Subcutaneous implant breast reconstruction: Time to reconsider? Eur J Surg Oncol 43: 1636-1646

56. Deo SV, Purkayastha J, Shukla NK, Asthana S (2003) Myocutaneous versus thoraco abdominal flap cover for soft tissue defects following surgery for locally advanced and recurrent breast cancer. J Surg Oncol 83: 31-35.

57. Peres AC, Latorre MD, Maesaka J, Filassi JR, Baracat E, et al. (2017) Body Posture After Mastectomy: Comparison Between Immediate Breast Reconstruction Versus Mastectomy Alone. Physiother Res Int.

58. Głowacka I, Nowikiewicz T, Siedlecki Z, Hagner W, Nowacka K, et al. (2015) The Assessment of the Magnitude of Frontal Plane Postural Changes in Breast Cancer Patients After Breast-Conserving Therapy or Mastectomy Follow-up Results 1 Year After the Surgical Procedure. Pathol Oncol Res 22: 203-208.

59. Jeong JH, Choi B, Chang SY, Kim EK, Kang E, et al. (2018) The Effect of Immediate Breast Reconstruction on Thoracic Spine Alignment After Unilateral Mastectomy. Clin Breast Cancer 18: 214-219.

60. Głowacka-Mrotek I, Sowa M, Nowikiewicz T, Siedlecki Z, Hagner W, et al. (2018) Foot posture in female patients 5 years after breast-conserving surgery: a case-control study. Breast Cancer 25: 325-333.

61. Rangel J, Tomás MT, Fernandes MB (2018) Physical activity and physiotherapy: perception of women breast cancer survivors. Breast Cancer 26: 333-338.

62. Dibai-Filho AV, de Jesus Guirro RR, Koga Ferreira VT, Kelly de Oliveira A, Maria de Almeida A, et al. (2018) Analysis of chronic myofascial pain in the upper trapezius muscle of breast cancer survivors and women with neck pain. J Bodyw Mov Ther 22: 237-241.

63. Hanuszkiewicz J, Malicka I, Barczyk-Pawelec K, Woźniewski M (2015) Effects of selected forms of physical activity on body posture in the sagittal plane in women post breast cancer treatment. J Back Musculoskelet Rehabil 28: 35-42.

64. Dieli-Conwright C, Orozco B (2015) Exercise after breast cancer treatment current perspectives. Breast Cancer Targets Ther 7: 353-362.

65. Ruddy KJ, Stan DL, Bhagra A, Jurisson M, Cheville AL, et al. (2017) Alternative exercise traditions in cancer rehabilitation. Phys Med Rehabil Clin 28: 181192.

66. Walowska J, Bolach B, Bolach E (2018) The influence of Pilates exercises on body balance in the standing position of hearing impaired people. Disabil Rehabil 40: 3061-3069.

67. Espíndula RC, Nadas GB, Rosa MID, Foster C, Araújo FC, et al. (2018) Pilates for women with breast cancer: A systematic review and meta-analysis. Complement Ther Med 41:130-140. 